\title{
COMÉRCIO JUSTO E DESENVOLVIMENTO PLURIDIMENSIONAL: UM OLHAR SOBRE AS POSSIBILIDADES NA SOCIEDADE EM REDE
}

\author{
Isadora K. Lazaretti ${ }^{1}$ \\ Giovanni Olsson ${ }^{2}$
}

\begin{abstract}
RESUMO: A presente pesquisa tem como escopo estudar o comércio justo e o desenvolvimento pluridimensional a partir de suas possibilidades na sociedade em rede. Pela intensificação da globalização, o comércio justo atinge o modelo de concorrência pela produção em massa e pelo peso simbólico e mercadológico das marcas. Trata-se de um movimento transnacional preocupado com condições de mercado e de consumo mais justas e almeja um alinhamento das práticas comerciais destinadas à promoção do desenvolvimento e da melhoria da qualidade de vida das comunidades. A pesquisa tem caráter qualitativo, e adotou-se o método dedutivo, utilizando-se a técnica de pesquisa bibliográfica.
\end{abstract}

Palavras-chave: comércio justo; desenvolvimento sustentável; Agenda 2030; sociedade em rede; globalização.

\section{FAIR TRADE AND MULTIDIMENSIONAL DEVELOPMENT: A LOOK AT THE POSSIBILITIES IN NETWORK SOCIETY}

\begin{abstract}
This research aims to study fair trade and multidimensional development along with its possibilities in network society. By intensifying globalization, the fair trade hits competition model of mass production and also by the symbolic and marketable weight of brands. It is a transnational movement concerned with fairer market and consumer conditions and aims at aligning trade practices at fostering development and improving the quality of life of communities. The research has a qualitative profile, and the deductive method was adopted, using the bibliographic research technique.
\end{abstract}

Keywords: fair trade; sustainable development; 2030 Agenda; network society; globalization.

\footnotetext{
${ }^{1}$ Mestre em Direito pela Universidade Comunitária da Região de Chapecó - UNOCHAPECÓ. Professora do Curso de Direito da Unochapecó.

${ }^{2}$ Doutor em Direito pela Universidade Federal de Santa Catarina. Professor do Programa de Pós-Graduação em Direito da Unochapecó.
} 


\section{INTRODUÇÃO}

O presente artigo tem como tarefa estudar o comércio justo e o desenvolvimento pluridimensional a partir de suas possibilidades na sociedade em rede. A escolha do tema e sua problematização se deu pela relevância, complexidade e atualidade dos debates envolvendo o desenvolvimento, como uma categoria conceitual, empírica ou crítica. Essa realidade expressase fortemente em razão dos impactos gerados pela emergência e propagação do fenômeno globalizante para além das fronteiras territoriais dos Estados.

A velocidade dos avanços tecnológicos no campo da telemática e dos transportes acarretou modificações significativas nos últimos tempos, formando uma sociedade que se estrutura a partir das redes, cuja visibilidade demonstra o impacto nas suas relações.

Nesse âmbito, atualmente, poucas são as temáticas que atraem os debates contemporâneos como aqueles ligados ao desenvolvimento. Trata-se de um tema desafiador que vem sendo discutido nos mais diversos campos do conhecimento e retrata objetivos de transformar o mundo e melhorar a qualidade de vida, com base na preocupação da presente e das futuras gerações. O desenvolvimento expressa um projeto civilizatório compartilhado que se preocupa com o meio ambiente e com o crescimento econômico, mas igualmente com diversas outras dimensões, como as relações sociais, políticas e jurídicas, na busca da promoção integral do ser humano em todos os seus espaços e papeis.

Com base nisso, o presente estudo visa analisar o comércio justo como um instrumento do desenvolvimento pluridimensional na sociedade em rede, cuja abordagem se realiza em vista de seus limites e possibilidades. Especificamente, busca-se compreender o desenvolvimento sustentável pluridimensional e o novo marco civilizatório; estudar a sociedade em rede no século XXI e seus protagonistas; e, por fim, investigar o comercio justo como um promotor do desenvolvimento na sociedade contemporânea.

Quanto aos aspectos metodológicos, adota-se na presente pesquisa o método dedutivo. Quanto ao método de procedimento, utilizam-se o histórico e o estruturalista, partindo do estudo do desenvolvimento sustentável. A pesquisa tem caráter qualitativo, e a técnica de pesquisa utilizada foi a bibliográfica. Com lastro nesses pressupostos metodológicos, a pesquisa está estruturada em três tópicos. No primeiro tópico, a atenção é dedicada para o estudo do desenvolvimento sustentável pluridimensional e o novo marco civilizatório do desenvolvimento sustentável na Agenda 2030 da Organização das Nações Unidades. No 
segundo tópico, são expostas as principais características da sociedade em rede e seus elementos de conformação na contemporaneidade. Por fim, no terceiro tópico, é feita uma análise do comércio justo enquanto promotor do desenvolvimento pluridimensional na sociedade contemporânea.

Assim, é necessário iluminar essa nova e incitante realidade, cujo tema, por si só, apresenta importância ímpar, porque desafia os modelos estabelecidos e até então intactos, e expressa uma imensa potencialidade na compreensão da sociedade contemporânea.

\section{DESENVOLVIMENTO SUSTENTÁVEL PLURIDIMENSIONAL E O NOVO MARCO CIVILIZATÓRIO}

O conceito de "desenvolvimento" vem sendo objeto de discussão pelo menos desde a década de 60, a partir da criação do Programa das Nações Unidas para o Desenvolvimento, que tinha como principal objetivo a redução das desigualdades entre países com níveis maiores de desenvolvimento em comparação a países menos desenvolvidos. Contudo, o conceito de desenvolvimento nesse período era discutido de forma genérica, especialmente direcionado para assuntos de caráter econômico (ONU, 2018).

Desenvolvimento, na concepção de Almeida-Scabbia e Bonini, está ligado diretamente com o crescimento de ativos sociais, uma vez que, na medida em que quanto mais se debate o desenvolvimento e quanto mais o desenvolvimento é o objetivo dos estudos sobre dinâmicas sociais, locais e regionais, maior será o seu aprimoramento, tendo em vista que esse processo resulta sempre em um retorno social, cultural, ambiental e econômico (2017, p.20).

Pensar sobre desenvolvimento, hoje, ultrapassa a noção que afirma a supremacia dos países desenvolvidos perante os subdesenvolvidos, uma vez que crescimento e desenvolvimento não podem ser considerados mais como sinônimos, porque seu conceito se tornou amplo e complexo, porque abrange uma série de variáveis sociais (BARBOSA, 2008, p. 111). Nos últimos vinte anos, os cientistas sociais trabalharam para atribuir clareza analítica para o atributo de sustentabilidade, e esses estudos trouxeram grandes avanços. O ponto fundamental diz respeito à associação de sustentabilidade, com projeção para o futuro, como se pode verificar no documento de 1987 (Brundtlandt) da Comissão Mundial de Meio Ambiente e Desenvolvimento: “o desenvolvimento sustentável busca encontrar as necessidades e 
aspirações do presente sem comprometer a habilidade de encontrar essas mesmas aspirações do futuro" (Capítulo I, Parágrafo 49) (DILLARD, DUJON e KING, 2009, p. 84-85).

O debate entre sustentabilidade e desenvolvimento sustentável, por sua vez, ganhou força a partir da publicação do Relatório "Nosso Futuro Comum", que fez prever a definição de desenvolvimento sustentável como eixo central do discurso público. A principal recomendação desse documento era que a organização do círculo de competências e demandas para a proteção ambiental e desenvolvimento econômico seria por meio do desenvolvimento sustentável (DRESNER, 2002, p.1).

Quanto ao desenvolvimento sustentável, de forma conjugada, sua afirmação decorre da preocupação de um desenvolvimento da sociedade que não prejudique as futuras gerações. Essa preocupação com o futuro foi destacada pelo filósofo alemão Hans Jonas (1903-1993) a partir da ideia da "ética da responsabilidade", porque, no mundo contemporâneo, em razão da altíssima tecnologia e de um vazio ético, o homem tem o poder e a capacidade pra destruir a natureza e prejudicar as futuras gerações (MARQUES, BARBOSA e ARAÚJO, 2017, p. 34).

A ideia de viver de forma sustentável tomou espaço nos debates a partir da década de 80 e se intensificou com sucessivas convenções da Organização das Nações Unidas. Como exemplo, no ano de 1992, na Eco 92, adotou-se a chamada "Agenda 21", que tinha como principal objetivo a preservação do planeta e o desenvolvimento sustentável, propondo novas concepções e planos para o crescimento econômico sustentável e para a prosperidade, na busca de permitir uma melhor qualidade de vida. Ela propugnava modificações no estilo de vida, para que houvesse menos dependência dos recursos limitados do planeta e mais harmônicos com a sua capacidade produtiva (ONU, 2018b).

No ano de 1997, a ONU revisou a Agenda 21, vindo a instituir metas vinculativas aos Estados. No mesmo sentido, em 2002, realizou-se a Cúpula Mundial sobre Desenvolvimento Sustentável, que teve como pano de fundo a avaliação das conquistas, dos desafios e das novas questões que se tornariam objeto de discussão nos próximos anos. Dez anos depois, realizouse a chamada Rio+20, cuja conferência teve como objetivo a avaliação dos avanços socioambientais desde a realização da Eco92, assim como verificar a necessidade na tomada de medidas para a proteção ambiental e social, impulsando, com isso, o desenvolvimento sustentável em uma acepção agora mais alargada (MARQUES, BARBOSA e ARAÚJO, 2017, p. 35). 
Em 2015, por fim, durante a realização da Cúpula do Desenvolvimento Sustentável, foi lançada a Agenda 2030, que consiste em um documento que abrange dezessete objetivos e cento e sessenta e nove metas, e configura um novo projeto civilizatório e um novo referencial sobre desenvolvimento sustentável (ONU, 2018c). Alcançar a sustentabilidade configura uma busca empreendida por pessoas e organizações que se envolvem em discursos e tomam ações no terreno da sociedade civil, com a intenção de mediar impactos e assegurar um futuro positivo para as gerações de hoje e de amanhã, a partir de perspectivas sociais, econômicas e ambientais (DILLARD, DUJON e KING, 2009, p. 73). A Agenda 2030, de forma inovadora, introduz expressamente o reconhecimento de que a sustentabilidade não é apenas um debate entre crescimento econômico e proteção ambiental, mas um projeto de múltiplas dimensões interdependentes.

$\mathrm{Na}$ academia, o estudo do desenvolvimento sustentável tem sido associado a uma serie de ideias normativas que incluem a proteção do meio ambiente, o bem-estar humano e a preocupação com as futuras gerações em todas as suas esferas (MEADOWCROFT, 2009, p.108). A ideia de desenvolvimento sustentável esteve sempre ligada à proteção ambiental. Contudo, a partir da Agenda 2030, o desenvolvimento sustentável se tornou reconhecidamente complexo, agora como um "processo multidisciplinar integrado econômico, social, ambiental e cultural" (BARBOSA, 2008, p.111).

O desenvolvimento sustentável constitui uma forma de desenvolvimento que, conforme definido pela Organização das Nações Unidas (2018c), “encontra as necessidades atuais sem comprometer a habilidade das futuras gerações de atender suas próprias necessidades", e que "requer que as sociedades atendam as necessidades humanas tanto pelo argumento do potencial produtivo como pela garantia de oportunidades iguais para todos".

Além disso, a população mundial vive numa realidade que vai além do debate sobre os recursos ambientais, de modo que o desenvolvimento sustentável deve buscar a preservação dos sistemas naturais que sustentam a vida na Terra, como, por exemplo, a atmosfera, as águas, os solos e os seres vivos. Tem-se, assim, o desenvolvimento sustentável como um verdadeiro "processo de mudança" onde "a exploração de recursos, o direcionamento dos investimentos, a orientação do desenvolvimento tecnológico e a mudança institucional estão em harmonia e reforçam o atual e futuro potencial para satisfazer as aspirações e necessidades humanas" (ONU, 2018c). 
A noção de desenvolvimento sustentável esteve historicamente interligada com as discussões da proteção ambiental enquanto um fator limitador para o crescimento econômico. Contudo, o desenvolvimento sustentável vai além da dimensão ambiental. Com o advento da Agenda 2030 da ONU, os objetivos e metas anunciados, integrados e indivisíveis, equilibram pelo menos três dimensões de desenvolvimento: a econômica, a social e a ambiental. Trata-se de um verdadeiro tripé, onde todas elas são relevantes igualitariamente e na mesma proporção, como expressamente anuncia o preâmbulo do documento e fica evidenciado pela amplitude e diversidade de seus objetivos (ONU, 2018c).

Freitas (2011, p. 55) defende a existência de cinco dimensões: a social, a ética, a jurídico-política, a econômica e a ambiental. Para ele, a dimensão social preocupa-se com a interação de todos os seres, de modo que a sustentabilidade está ligada à eficácia dos direitos e das políticas públicas relacionadas com a saúde, trabalho, educação, segurança, moradia e outros direitos fundamentais sociais. A dimensão ética se funda na premissa de que a sustentabilidade exige uma ação que vise além do bem-estar íntimo de cada indivíduo, isto é, o bem-estar social (FREITAS, 2011, p.58). A dimensão econômica, por sua vez, está ligada a eliminação da pobreza e das desigualdades. Na dimensão jurídico-política, segundo Freitas (2011, p. 63), “a busca da sustentabilidade é um direito; e encontra-la é um dever constitucional inalienável e intangível de reconhecimento da liberdade”. E, ainda, existe a dimensão ambiental, que está diretamente ligada à ideia de dignidade do meio ambiente e expressa a preocupação de proporcionar às futuras gerações um "ambiente limpo" (FREITAS, 2011, p. 60). Na sua configuração atual, o desenvolvimento sustentável vem sendo caracterizado como "um novo valor moral, ético e político e jurídico de grande importância, capaz de gerar direitos e deveres humanos e fundamentais” (DE MARCO e MEZZAROBA, 2017, p. 332).

O objetivo da Agenda 2030 da ONU, em linhas gerais, consiste na manutenção de compromissos, para que seja possível o acesso dos indivíduos a uma vida de qualidade, com a superação da pobreza e o alcance da busca social pela redução das desigualdade sociais e a garantia efetiva e plena dos direitos fundamentais e programas relacionados à saúde, educação e segurança (HÜLSE e PASOLD, 2018).

O desenvolvimento sustentável deve ser considerado como o novo marco civilizatório a partir da Agenda 2030 da ONU, e deve ser analisado enquanto um autêntico novo paradigma. O desenvolvimento sustentável configura um "processo de ampliação permanente das liberdades substantivas dos indivíduos em condições que estimulem a manutenção e a 
regeneração dos serviços prestados pelos ecossistemas às sociedades humanas". O desenvolvimento sustentável abrange ainda uma série de fatores cujo andamento depende "da presença de um horizonte estratégico entre seus protagonistas decisivos" (ABRAMOVAY, 2015).

Por fim, o desenvolvimento sustentável no projeto civilizatório da Agenda 2030 da ONU envolve uma reformulação de conceitos, cuja compreensão se faz necessária na sociedade contemporânea para a concretização, promoção e efetivação dos objetivos e metas do milênio. Assim, analisado o desenvolvimento sustentável pluridimensional nesse novo marco, passa-se ao estudo da sociedade em rede no século XXI, que constitui exatamente a tessitura das relações entre os principais atores envolvidos na promoção desses objetivos.

\section{A SOCIEDADE EM REDE NO SÉCULO XXI}

Com a emergência do fenômeno da globalização, passou-se a perceber que as distâncias parecem ficar menores e o tempo parece ficar mais curto (OLSSON, 2003, p. 90). Uma nova percepção veio à tona, marcada pela noção de "compressão" ou "encurtamento" do espaço e do tempo. Essa percepção é compreendida como uma "aceleração do mundo", como um verdadeiro reflexo do fenômeno globalizante. Para Santos (1998, p. 192), essa aceleração constitui “[...] um resultado também da banalização da invenção do perecimento prematuro dos engenhos e de sua sucessão alucinante".

Essa nova realidade fez com que emergisse a ideia de que o ser humano vive em uma sociedade em rede. Em sua obra clássica, McLuhan já analisava as consideráveis transformações que assolaram a humanidade nos últimos séculos. Para o autor, "as extensões do homem", pelos avanços da "era da eletrônica", já disseminavam em "meios quentes e frios", refletindo em diversos setores que fazem parte da vida em sociedade, como na economia, no comércio, na política. O impacto tecnológico fez com que emergisse um ambiente humano totalmente reconfigurado (McLUHAN, 2001, p. 10).

O rápido avanço dos meios de comunicação, meios de transporte e da informática reconfiguraram a sociedade, sobrevindo a chamada "era da informação". Castells (2006, p. 57) refere que a era informacional é o resultado desse processo globalizante e dos avanços tecnológicos, que permite o processamento de dados de forma imediata, transformando-se a 
sociedade internacional pelo surgimento de novos instrumentos que passam a fazer parte do mundo em redes.

A revolução nas tecnologias da informação fez com que emergisse uma nova sociedade, uma nova economia e uma nova cultura, "integrando o mundo em redes globais de instrumentalidade" (CASTELLS, 2006, p. 57). Nessa linha, essa revolução é caracterizada não comente pela centralidade dos conhecimentos e da informação, mas pela “[...] aplicação desses conhecimentos e dessa informação para a geração de conhecimentos e de dispositivos de processamento/comunicação da informação, em um ciclo de realimentação cumulativo entre a inovação e seu uso" (CASTELLS, 2006, p. 69).

Nesse sentido, McLuhan entende que “[...] os novos meios e tecnologias pelos quais nos ampliamos e prolongamos constituem cirurgias levadas a efeito no corpo social com o mais completo desdém pelos anestésicos”. Continua o referido teórico ao alertar que, “[...] ao se operar uma sociedade com uma nova tecnologia, a área que sofre a incisão não é a mais afetada. A área da incisão e do impacto fica entorpecida. O sistema inteiro é que muda" (McLUHAN, 2001, p. $84)$.

A revolução tecnológica é globalizante, de modo que tudo é aqui e agora. Essa revolução se encontra em constante transformação, e configura um fenômeno recente que conduz a sociedade internacional para rumos desconhecidos, porque esse processo é um caminho sem destino definido. Pode-se dizer que se vive a "era da rede global”, devido ao seu inusitado fenômeno da comunicação instantânea, cujos efeitos são reflexos da Revolução Tecnológica Informacional (OLIVEIRA, 2016, p. 16).

A sociedade em rede é característica dos tempos atuais, de modo que tal afirmação não constitui nenhuma novidade, mas seu estudo demanda uma análise aprofundada. Reconhecer a sociedade em rede, de forma viva e pulsante, se faz fundamental para entender os limites e as possibilidades da organização social (OLSSON, 2016, p. 88).

Para Castells (2006, p. 566), “[...] redes são estruturas abertas capazes de expandir de forma ilimitada, integrando novos nós desde que consigam comunicar-se dentro da rede, ou seja, desde que compartilhem os mesmos códigos de comunicação". Ou, ainda, a rede pode ser conceituada como “[...] um conjunto de nós interconectados. Nó é o ponto no qual uma curva se entrecorta. Concretamente, o que um nó é depende do tipo de redes concretas de que falamos" (CASTELLS, 2006, p. 566). 
A título exemplificativo, a rede pode ser tanto "[...] mercados de bolsas de valores e suas centrais de serviços auxiliares avançados na rede dos fluxos financeiros globais [...]" como também podem ser "conselhos nacionais de ministros e comissários europeus da rede política que governa a União Europeia”, ou, ainda, “[...] sistemas de televisão, estúdios de entretenimento, meios de computação gráfica, equipes para cobertura jornalística e equipamentos móveis gerando, transmitindo e recebendo sinais na rede global da nova mídia [...] na era da informação" (CASTELLS, 2006, p. 566). As redes podem ser estruturadas mediante uma variedade de desenhos, como modelos simples que se formam em cadeia ou linhas, ou, modelos completos que se formam em raios ou estrelas. Podem ainda ser complexos, como o caso dos "multicanais", de modo que cada um desses modelos pode se articular e formar redes de múltiplos raios (OLIVEIRA, 2016, p. 18).

São, dessa forma, entendidas por estruturas comunicativas, processadoras de fluxos, correntes de informação, que circulam os canais de conexão que se formam em raios e nós. As redes cooperam umas com as outras, e essa cooperação se baseia na capacidade de comunicação que ocorre entre as redes, em razão da "existência de códigos de tradução e interoperabilidade entre elas" (CASTELLS, 2015, p. 66-67). As redes não são uma construção específica das sociedades do século XXI, tampouco da organização humana. Constituem, em verdade, "um modelo de vida" (CASTELLS, 2015, p. 67). As redes constituem uma "nova morfologia social" presente na nossa sociedade, sendo que "[...] a difusão da lógica de redes modifica de forma substancial a operação e os resultados dos processos produtivos e de experiência, poder e cultura". Para Castells (2006, p. 565), a sociedade em rede configura um novo paradigma de tecnologia e de informação, que "fornece a base material para sua expansão penetrante em toda a estrutura social"'.

A emergência da rede ocorre a partir de aspectos evolutivos, que se manifestam em quatro fases. Primeiramente, surge na forma de "agrupamentos disseminados e escassamente conectados". Em seguida, a rede pode desenvolver conexões, vindo a atingir "a forma de raios ou estrelas, quando então e, se for o caso, atingir novo estágio de múltiplos rádios, formando um pequeno mundo". Se a rede continuar avançando, seja em amplitude ou em extensão, “converter-se-á finalmente em uma complexa rede de núcleo-periferia" (OLIVEIRA, 2016, p. 19).

Dessa forma, a sociedade em rede se expressa em vários segmentos e campos. $\mathrm{Na}$ política, por exemplo, ela "reconfigura os referenciais". Reconhece-se que "os fundamentos da 
legitimidade e responsabilidade dos atores nos processos políticos estão sendo radicalmente alterados". Ocorre uma transformação total de cenário, uma vez que a imagem dos atores políticos passa a ser desconstruída pela mídia e a transparência das ações políticas também contribuem para que ocorra a chamada "governança sem governo" (OLSSON, 2016, p. 92).

A atual revolução tecnológica é marcada pela sociedade em rede, e seus desenhos se verificam pela ampliação de conhecimentos e informações, bem como pela criação de dispositivos de processamento de dados. Nesse viés, “[...] a tecnologia da informação é para esta revolução o que as novas fontes de energia foram para as revoluções industriais sucessivas, do motor a vapor à eletricidade, aos combustíveis fósseis e até mesmo à energia nuclear" (CASTELLS, 2006, p. 68-69).

Rede é, portanto, um “conjunto de nós interconectados”, definição adotada por Castells (2015, p. 66). Na sua concepção, cada nó da rede possui uma importância específica que pode variar de acordo com sua função e significado. Os mais importantes são chamados pelo autor de "centros", porém qualquer componente da rede é um nó e ele interage com os demais nós dessa rede. Por fim, destaca que "[...] a importância dos nós para a rede aumenta de acordo com sua capacidade de absorver informações mais relevantes e de processá-las de maneira mais eficiente" (CASTELLS, 2015, p. 66).

As redes são capazes de introduzir novos atores e conteúdos no processo organizativo social, e isso se deu por conta dos avanços tecnológicos, especialmente no campo das comunicações. Com isso, as redes se tornam formas organizacionais eficientes, de modo que tal resultado está ligado às suas três principais características: a flexibilidade, a escalabilidade e a capacidade de sobrevivência.

A flexibilidade pode ser definida como "[...] a habilidade da rede de se reconfigurar de acordo com as mudanças ambientar e de manter suas metas ao mesmo tempo que muda seus componentes". A escalabilidade constitui "a capacidade de expandir ou encolher em tamanho sem grandes interrupções”. Por fim, a capacidade de sobrevivência é "[...] a capacidade que as redes têm de suportar ataques aos seus nós e a seus códigos em virtude de não terem um único centro e poderem operar em diversas configurações" (CASTELLS, 2015, p. 69).

A partir da utilização das redes, em especial, as de tecnologia informacional, esta pode "auxiliar as pessoas, os atores, a agirem e tomarem decisões". Dessa forma, o advento e a utilização das novas tecnologias informacionais e de comunicação “[...] são características predominantes em diversos protestos reivindicatórios ocorridos pelo mundo, sobretudo, 
ajudando a propagar ideias e ideais, em diversas situações, contextos e interesses" (MAIA, 2016, p. 304).

Importa salientar ainda que o universo das redes se apresenta em três formas diferentes: rede centralizada, descentralizada e distribuída. A rede centralizada está configurada pela existência de uma organização central, que, em que pese estar ligada a outras redes de forma individual, as que se interligam com a rede central não se ligam com as demais. A rede descentralizada abrange redes ligadas umas às outras, mas não de forma exclusiva. Por fim, a rede distribuída é formada por pontos que se ligam uns aos outros, de forma direta ou indireta (UGARTE, 2007, p. 8).

A rede consegue atingir os níveis mais fundamentais da sociedade, como as pessoas e os lugares, como no caso dos atores não-estatais. A rede tende a " [...] criar ligações de acordo com projetos e programas que desenvolvem e procuram trabalhar, com seus nós e interseções, com o mínimo da intervenção estatal, o que se configura como a sociedade informacional global” (OLIVEIRA; ZEFERINO, 2016, p. 167).

É possível considerar ainda, levando em conta os ideais de Castells (2015, p. 71), que a sociedade em rede é capaz de se espalhar de forma gradativa e seletiva por todo o planeta, se expressando em diversos locais, culturas, organizações e instituições que compõem o habitat natural da vida humana. Nesse sentido, “[...] a estrutura social é global, mas a maior parte da experiência humana é local, tanto em termos territoriais quanto culturais".

O funcionamento das redes nesse cenário garante o substrato reestruturante das sociedades. As redes constituem um espaço de fluxos com distâncias ilimitadas, sendo capazes de expandir suas estruturas e de proporcionar a flexibilidade necessária para produzir a inovação. Dessa forma, “as redes se reinventam e se reorganizam” (DE FAZIO, 2012, p. 34).

A transformação tecnológica, baseada, conforme entende Castells, na digitalização da comunicação, fundada nas redes de computadores e em softwares mais avançados, bem como na transmissão de dados em larga escala, encontra-se generalizada por meio da existência das redes sem fio, possibilitando, assim, a facilidade cada vez maior de acessar à internet. Além disso, emissores e receptores são, segundo Castells (2015, p. 102), “a mídia e seu chamado público". Dessa forma, assim como considerou McLuhan (2001, p. 11), estamos inseridos em um ambiente totalmente novo, cujo conteúdo é caracterizado pelo "velho ambiente mecanizado da era industrial". Esse novo ambiente "reprocessa o velho tão radicalmente quanto a TV está processando o cinema". Ademais, "[...] as consequências sociais e pessoais de qualquer meio 
[...] constituem o resultado do novo estalão introduzido em nossas vidas por uma nova tecnologia ou extensão de nós mesmos" (McLUHAN, 2001, p. 21).

Por fim, a sociedade contemporânea é marcada pela informação e pelo conhecimento, uma vez que as tecnologias deram novas modelagens à organização social, transformando-a em uma sociedade em rede. Porém, essa sociedade continua a ser capitalista, ainda que de forma diferente de seus registros históricos: "é global e está estruturado, em grande medida, em uma rede de fluxos financeiros". Verifica-se que os níveis mais fundamentais da sociedade hoje se manifestam em rede, tendo em vista que os processos de transformação ultrapassaram a esfera das relações sociais, afetando as bases mais significativas da sociedade, do espaço e do tempo (CASTELLS, 2006, p. 567-572). Dessa forma, estudada a formação da sociedade em rede e seu protagonismo no cenário complexo que se manifesta no século XXI, passa-se a analisar o comércio justo enquanto um instrumento de promoção do desenvolvimento na sociedade contemporânea.

\section{COMÉRCIO JUSTO COMO PROMOTOR DE DESENVOLVIMENTO NA SOCIEDADE CONTEMPORÂNEA}

Com a emergência do fenômeno da globalização, uma nova releitura do capitalismo em nível mundial veio à tona, além de uma importante etapa do progresso da internacionalização (CHESNAIS, 1996, p. 13). Trata-se, segundo Faria (1999, p. 52), de “[...] uma integração de natureza eminentemente sistêmica, acima de tudo alicerçada na especialização e 'mercantilização' do conhecimento, na eficiência, na tecnologia, na competitividade, na produtividade e no dinheiro".

O capitalismo irrefreável se encontra caracterizado por uma maior flexibilidade de gerenciamento, e verifica-se a descentralização das empresas e sua organização em redes, seja de forma interna, seja em suas relações externas com outras empresas ou Estados. Emerge um verdadeiro "mundo de fluxos globais de riqueza, poder e imagens", de modo que "[...] a busca da identidade, coletiva ou individual, atribuída ou construída, torna-se a fonte básica de significado social" (CASTELLS, 2006, p. 41).

Com a intensidade com que tal fenômeno passou a se manifestar, associaram-se o capital e a tecnologia, juntamente com as comunicações e a informática, resultando nas chamadas "redes telemáticas globais". É por conta dessas redes que o sistema financeiro se 
expressa, de modo que se tornou possível a transferência imediata de recursos financeiros para qualquer parte do mundo (FARIA, 1999, p. 68).

É a partir dessa aceleração que o consumidor e o consumismo passaram a ganhar maior importância nas relações sociais, emergindo questões ligadas ao consumo e a sustentabilidade, especialmente com aspectos ligados ao consumo consciente e responsável. Nessas situações, o Comércio Justo ganha espaço como um dos mais emblemáticos exemplos. A realidade do comércio mundial de bens e serviços gerou uma série de conflitos, especialmente com o aumento das desigualdades sociais, diante da diversidade na distribuição de riquezas e do fomento da igualdade material entre os Estados (STELZER, TODESCAT e GONÇALVES, 2016, p.19-20).

A revolução tecnológica e informacional se assemelha com os desenhos da antiga Revolução Industrial, uma vez que a emergência desse novo contexto desencadeou consideráveis modificações nas bases da economia e da sociedade. Contudo, a informação e a comunicação constituem o diferencial dessa nova era, tendo como base novos conhecimentos científicos e tecnológicos (DE FAZIO, 2014, p. 344).

Diante da expansão do modelo industrial de produção, a conformação da sociedade de consumo no século XX foi a responsável pela promoção dos padrões de compra em massa e das campanhas de marketing. A oferta geralmente excedia a demanda, refletindo diretamente nos padrões de consumo, porque as estratégias adotadas estimulavam ainda mais o consumismo, gerando impactos ambientais, sociais, econômicos e culturais (MASCARENHAS e GONÇALVES, 2016, p. 120).

A respeito da formação da sociedade de consumo, Bauman atenta que ela é marcada por uma forma de pensar individualista da população, e representa "o tipo de sociedade que promove, encoraja ou reforça a escolha de um estilo de vida e um estratégia existencial consumista, e rejeita todas as opções culturais alternativas" (2008, p.70). Para ele, a sociedade dos consumidores é instigada pela prática do marketing e pelo design de novos produtos, resultando em uma verdadeira exaltação de ofertas, a partir de um consumo desnecessário pelos indivíduos.

Diante da velocidade dos avanços tecnológicos, proporcionados pelos impactos globalizantes, a troca de bens e o ritmo de produção de novos produtos está cada vez mais intensa, enraizando a cultura do "hiperconsumo", cuja prática vem sendo incorporada pelos indivíduos como um modo de viver, em que produtos são consumidos, destruídos e descartados 
em ritmo cada vez maior" (LIPOVETSKY, 2007, p. 67). Em outras palavras, a globalização proporcionou um estilo de vida em que a sociedade vive "o tempo dos objetos" (BAUDRILLARD, 2007, p. 15).

A realidade do comércio mundial colocou em dúvidas as "fórmulas liberalizantes" do sistema de trocas, com a riqueza distribuída de forma desigual entre os Estados. Nessa sociedade marcada pelo capitalismo e pelo hiperconsumismo, novas práticas comerciais passaram a ser discutidas e experimentadas, tendo em vista que as promessas do livre comércio não lograram êxito em trazer a esperada igualdade de tratamento entre as sociedades (STELZER, TODESCAT e GONÇALVES, 2016, p.21).

Dentre essas práticas, destaca-se o comércio justo, que configura um movimento socioeconômico global que propõe uma forma diferente para entender as relações econômicas e comerciais que se manifestam na sociedade contemporânea. Essa prática nasceu como uma resposta para as relações negociais que não contribuem para o desenvolvimento sustentável, no que diz respeito à erradicação da pobreza, promoção e efetivação dos direitos humanos, redução das desigualdades sociais e preservação e respeito ao meio ambiente (COSCIONE e MULDER, 2017, p. 19).

O comércio justo pode ser definido como "um movimento de dimensões múltiplas (social, econômica, ambiental, política) que se apresenta na qualidade de alternativa ao comércio convencional, regido por valores éticos e que se preocupa com toda a cadeia logística" (STELZER, TODESCAT e GONÇALVES, 2016, p. 21).

Asti (2016, p. 312) destaca que o comércio justo constitui "um sistema de mercado alternativo construído por grupos de produtores em desvantagem econômica de países do Hemisfério Sul e consumidores do Hemisfério Norte”. Nessa linha, nos países desenvolvidos, o comércio justo se verifica quando um setor crescente de consumidores compra produtos como uma forma de ajudar os produtores de baixa renda nos países que se encontram em desenvolvimento. Contudo, o comércio justo ultrapassa a noção de apenas garantir preços considerados "mais justos", porque, em muitas relações comerciais, as oportunidades de desenvolvimento se tornam escassas e desiguais, especialmente para os agricultores, camponeses e artesãos, se comparados com os atores dominantes do mercado de consumo. Não se pode negar, por exemplo, que existe uma desvantagem e uma flagrante desproporcionalidade entre essa classe de agentes e as grandes corporações. 
Nesse sentido, Coscione e Mulder (2017, p. 18) consideram que o movimento do comércio justo tem como escopo a construção de "cadeias de produção e consumo que contribuam para a distribuição mais equitativa em termos econômico, social e político". Na visão desses autores, “o comércio justo é um modelo de negócio que coloca os seres humanos no centro e sustentabilidade social, econômica e ambiental das sociedades, em vez de maximização dos lucros". Trata-se, assim, de uma prática que visa garantir a dignidade para o trabalho de todos os indivíduos envolvidos na cadeia de consumo e de valor, fomentando uma gestão de recursos responsável, e sustentável e natural.

Também conhecido como Fair Trade entre os produtores de países como Ásia, África e América Latina e operadores comerciais da Europa e dos Estados Unidos, o comercio justo configura uma prática inovadora, sistematizada pelos atores da sociedade civil, que surgiu motivado pelas dificuldades enfrentadas pelos produtores no mercado internacional, como forma de diversificar e possibilitar o acesso ao mercado de consumo por meio de práticas justas de negócio (TORRES, 2016, p. 367).

O principal objetivo do comércio justo é garantir aos pequenos produtores agrícolas e artesãos um acesso direto e justo ao mercado, possibilitando a introdução de seus produtos em condições equitativas, com base na solidariedade e na sustentabilidade. Essa prática configura, assim, uma forma de engajar o desenvolvimento das comunidades e de seus membros (COSCIONE e MULDER, 2017, p. 19).

Para Asti (2016, p. 299), o comércio justo recebe apoio direto de um forte posicionamento político que visa influenciar instituições que regem as normas do mercado, bem como sensibilizar o consumidor e o poder público, no intuito de aliar ações políticas a essas práticas comerciais. Na sua concepção, trata-se de "um movimento que se consolida em torno de três componentes principais: lojas especializadas; grande distribuição, ou "mainstream"; e sensibilização política".

Um dos principais objetivos do comércio justo consiste em incentivar a cultura de um consumo responsável, com a finalidade que os cidadãos compreendam a importância de comprar produtos advindos de cadeias de comércio justo e sustentável. Enquanto isso, os produtores utilizam-se dos benefícios do comércio justo para melhorar e aprimorar suas condições sociais e econômicas, especialmente entre os membros mais desfavorecidos. Tratase de uma prática associativa de mudança e desenvolvimento (COSCIONE e MULDER, 2017, p. 19). 
Os debates do comércio justo se intensificaram especialmente a partir dos primeiros anos do século XXI, direcionados para a análise dos impactos do comércio justo no desenvolvimento sustentável. Isso porque, através da rede, o mercado doméstico está sendo impulsionado ao consumo de produtos de comércio justo, uma vez que há demanda de consumidores comprometidos e dispostos a mudar seus padrões de consumo, pagando um preço que vise cobrir não apenas os custos de produção mas, ainda, promover a sustentabilidade e o desenvolvimento (COSCIONE e MULDER, 2017, p. 80).

O comércio justo configura uma estratégia de desenvolvimento sustentável, garantindo-se aos trabalhadores condições de vida plena, proporcionando, desta forma, o crescimento econômico integral às comunidades das quais esses trabalhadores estão inseridos (GONÇALVES e STELZER, 2013, p.4).

Essa estratégia consiste na verificação de práticas comerciais fundadas no diálogo, transparência, respeito e justiça, que contribuem para o desenvolvimento sustentável na medida em que oferecem melhores condições nas relações comerciais entre pequenos produtores e trabalhadores desfavorecido, resguardando e assegurando seus direitos (GUERRA, 2016, p.251). O movimento do comércio justo também pode ser estudado a partir da ótica da sua natureza de movimento social. Nesse sentido, sua manifestação ocorre por meio de ações coletivas, porque, além de exigir a participação de diversos indivíduos, essa atuação conjunta pressupõe o comprometimento de verdadeiras redes de colaboração mútua, já que o comércio justo configura um instrumento que visa também a erradicação das desigualdades, da pobreza e das crises econômicas.

Essa atuação em rede passou a se manifestar a partir dos anos 80, pelas redes internacionais de organização do comércio justo. Essas redes se estruturam com base no tipo de ator participante, sendo os produtores (WFTO), importadores (EFTA), Lojas (NEWS!), e certificadores (FT-International). Para Torres, “essas organizações permitiram aos atores articular, intercambiar, comunicar melhor e reforçar o impacto do comércio justo no âmbito global, em termos de eficiência econômica e também política" (2016, p. 385).

A respeito da formação das redes, De Fazio (2012, p. 105) destaca que elas são úteis igualmente a todos os setores que integram a sociedade. As redes compõem a estrutura sobre a qual se encontra o fenômeno da globalização, abrindo espaços para novos fluxos, permitindo a articulação de relações sociais. O uso das redes “'[...] faz surgir nova forma de articulação social 
e novo tipo de ação política, que encontram no espaço virtual o seu principal campo de manifestação" (DE FAZIO, 2012, p. 105-106).

É possível afirmar que a Internet é, hoje, a ferramenta mais utilizada no âmbito das redes, e sua utilização ocasiona a "[...] desfragmentação da comunicação que antes estava localizada dentro das fronteiras nacionais, atingindo o nível global transnacional”. A década de 1990 mostrou o valioso poder que a Internet exerce sobre a comunicação, e constitui um dos mais importantes resultados dos avanços tecnológicos, com a criação de computadores, da web e dos softwares (SILVA, 2016, p. 249-250).

Com o surgimento da Internet, emergiu uma nova cultura, definida por Silva (2013, p. 119) como "virtualidade real". Dessa forma, um dos níveis fundamentais da cultura informacional da Internet são as chamadas "comunidades virtuais" que se expressam, dentre outras modalidades, por meio das redes sociais. Essas comunidades virtuais exercem um importante papel nas novas formas de sociabilidade mantidas entre os indivíduos de uma sociedade. Para Silva (2013, p. 123), a Internet é a rede mais utilizada no mundo porque inúmeros são os usuários conectados a redes por conta da Internet no ciberespaço, "[...] onde a interação se dá com atores que representam signos em fluxo na rede, que podem ou não coincidir com pessoas do mundo real".

A internet e as redes sem fio foram responsáveis por fornecer aos aglomerados de mídia novos mercados voltados para a publicidade, transformando em mercadorias os meios de comunicação e a informação. Nessa linha, cada vez mais produtos de mídia são distribuídos e consumidos de forma on-line, resultados da formação e utilização das redes sociais pelos usuários, fazendo com que a publicidade reste cada vez mais articulada face o comportamento dos usuários. As principais atividades que modelam e monitoram a vida do homem são organizadas em redes globais, como os mercados financeiros, a ciência e a tecnologia, os esportes, os transportes, a cultura, a distribuição de bens e serviços, as redes da internet, a arte, a mídia, dentre outras. Nesse sentido, “[...] a globalização deve ser considerada a conexão em rede de todas essas redes globais socialmente importantes” (CASTELLS, 2015, p. 71).

Nesse viés, as redes de comércio justo são relacionadas com objetivos gerais, como, por exemplo, a luta contra a pobreza, o alcance da solidariedade e da cooperação internacional, o acesso aos mercados dos países do Norte. Com base nesses objetivos, é possível considerar que o comércio justo constitui um instrumento para a promoção no desenvolvimento 
sustentável e, ainda, uma ferramenta de emancipação para um projeto de economia alternativa ao modelo dominante (TORRES, 2016, p.384).

O comércio justo, segundo Stelzer, marca o crescimento das localidades e possibilita o relacionamento integrado entre povos de diferentes culturas. Fundado na ideia de desenvolvimento sustentável, o comércio justo almeja um alinhamento inédito e práticas comerciais destinadas a melhoria da qualidade de vida das comunidades, no contexto de regras justas (STELZER e WIEIRA, 2017, p.27).

A transnacionalização da globalização resultou em uma série de consequências, como a desterritorialização, a expansão do capitalismo, o enfraquecimento da soberania dos Estados e a emergência de ordenamentos jurídicos criados à margem do monopólio estatal. Em que pese tais desdobramentos, esse fenômeno proporcionou também o sistema embrionário do comércio justo, que, por meio das redes de colaboração solidária, por exemplo, consegue criar regras e critérios de justiça nas práticas comerciais, proporcionando inclusão social, bem-estar, cooperação e promoção do desenvolvimento (STELZER e GONÇALVES, 2017, p. 63).

No âmbito do desenvolvimento sustentável, dentre os objetivos elencados pela Agenda 2030 da ONU, destaca-se o alcance da erradicação da pobreza, o acesso ao emprego digno e o crescimento econômico, a redução das desigualdades sociais e a promoção das sociedades pacíficas e inclusivas para o desenvolvimento sustentável. Esses objetivos podem estar sendo alcançados por meio da prática do comércio justo, porque, além de ajudar os produtores diretamente envolvidos, pode ainda contribuir ao desenvolvimento das comunidades, territórios, regiões ou países.

O comércio justo, assim, configura uma alternativa de solução para modificar o tradicional sistema comercial internacional, marcado pelo protagonismo e pelo poder dominante das empresas transnacionais, para que práticas justas de comércio sejam observadas para proporcionar, por meio dessa rede de colaboração solidária, o desenvolvimento em sua sustentabilidade pluridimensional em comunidades em todo o mundo. 


\section{CONSIDERAÇÕES FINAIS}

Esse breve estudo sobre o comércio justo e desenvolvimento pluridimensional na sociedade em rede gera discussões e reflexões inquietantes. O desenvolvimento configura um tema central de debate na contemporaneidade, assim como o comércio justo, diante dos novos conceitos e emergentes práticas em favor da sustentabilidade, do consumo responsável, da cooperação, das organizações associativas em rede e nas iniciativas de promoção do desenvolvimento econômico, social e ambiental.

Verificou-se que o desenvolvimento sustentável configura um novo marco civilizatório a partir da Agenda 2030 da Organização das Nações Unidas, e sua afirmação configura um passo extremamente importante para o futuro da humanidade. A Agenda $2030 \mathrm{da}$ ONU constitui um plano de ação que elenca objetivos e metas que devem ser buscados e efetivados até o ano de 2030. Dentre eles, e como objeto geral dessa pesquisa, encontram-se a erradicação da pobreza, o acesso ao emprego digno e o crescimento econômico, a redução das desigualdades sociais e a promoção das sociedades pacíficas e inclusivas para o desenvolvimento sustentável, por exemplo.

A partir dessa análise, foi possível compreender que a sociedade em rede, resultado do processo de globalização, se manifesta por meio de várias formas na contemporaneidade, como, por exemplo, nas práticas comerciais, especialmente no mercado doméstico e no mercado internacional de consumo, onde se verificam novas práticas e padrões de consumo, como o comércio justo.

Essa prática configura uma estratégia de desenvolvimento destinada ao alcance do estabelecimento de condições mais justas nas práticas comerciais entre países consumidores e produtores e aqueles países que encontram-se em desenvolvimento, com base nos valores da economia solidária e do desenvolvimento sustentável. Além disso, é compreendido como um movimento transnacional que se manifesta em rede que visa justamente o estabelecimento de padrões de consumo equilibrados nas cadeias produtivas e pautado na sustentabilidade.

Com base na sua manifestação em rede, o comércio justo materializa o senso de justiça nas relações comerciais no mercado, visando a promoção do desenvolvimento sustentável a partir da redução das desigualdades entre as nações, por meio de uma proposta que se baseia na parceria e oferece melhores condições e possibilidades da garantia de uma vida 
digna. Nesse contexto, constitui uma interessante alternativa para a efetivação dos objetivos de desenvolvimento sustentável em análise.

\section{REFERÊNCIAS}

ABRAMOVAY, Ricardo. Desenvolvimento sustentável: qual a estratégia para o Brasil? Novos Estudos, n. 87, p.97-113, jul.2010. Disponível em:<http://www.scielo.br/pdf/nec/n87/a06n87.pdf >. Acesso em: 28 jul. 2018.

BONINI, Luci Mender de Melo; ALMEIDA-SCABBIA, Renata Jimenez de. Dinâmicas sociais e desenvolvimento local. In: BONINI, Luci Mendes de Melo et al. (Orgs.). Dinâmicas sociais e desenvolvimento local. Curitiba: CRV, 2017, p. 15-26.

BARBOSA, Cláudia Maria. Reflexoes para um Judiciário Socioambientalmente responsável. Revista da Faculdade de Direito UFPR. [S.L], dez.2008. ISSN 2236-7284. Disponível em: http://revistas.ufpr.br/direito/article/view/15744/10449. Acesso em: 01 ago. 2018.

BAUDRILLARD, Jean. A sociedade de consumo. Tradução de Artur Morão. Lisboa: Edições 70, 2007.

BAUMAN, Zygmunt. Vida para consumo: a transformação das pessoas em mercadorias. Tradução: Carlos Alberto Medeiros. Rio de Janeiro: Editora Zahar, 2008, p. 70.

CASTELLS, Manuel. A sociedade em rede. São Paulo: Paz e Terra, 2006. Terra, 2015.

O poder da comunicação. Tradução Vera Lucia Mello Joscelyne. São Paulo: Paz e

CHESNAIS, François. A mundialização do capital. Tradução Silvana Finzi Foá. São Paulo: Xamã, 1996.

DE MARCO, Cristhian Magnus; MEZZAROBA, Orides. O direito humano ao desenvolvimento sustentável: contornos históricos e conceituais. Revista Veredas do Direito. Belo Horizonte, v.14, n.29 ž p.323-349, Mai./Ago. de 2017.

DE FAZIO, Marcia Cristina Puydinger. A sociedade civil global e a rede: resistência à globalização desde cima? Ijuí: Ed. Unijuí, 2012.

FARIA, José Eduardo. O direito na economia globalizada. São Paulo: Malheiros Editores, 1999.

FREITAS, J. Sustentabilidade: direito ao futuro. Belo Horizonte: Fórum, 2011.

HÜLSE, Levi; PASOLD, Cesar Luiz. Práticas associativas em prol da sustentabilidade em Caçador, Santa Catarina, Brasil. Revista Justiça do Direito. Faculdade de Direito de Passo Fundo. $\quad$ v. $\quad 32, \quad$ n. $\quad 1, \quad 2018 . \quad$ Disponível $\quad$ em <http://seer.upf.br/index.php/rjd/article/view/8114/4800>. Acesso em 22 jul. 2018.

LIPOVETSKY, Gilles. A felicidade paradoxal: ensaios sobre a sociedade de hiperconsumo. Trad. Maria Lúcia Machado. São Paulo: Companhia das Letras, 2007. 
MAIA, Claudio Machado. Abordagens não dicotômicas do desenvolvimento: ação a distância, tecnologia informacional e o posicionamento estratégico de atores. In: OLIVEIRA, Odete Maria de (Org.). Relações internacionais, direito e poder: atores não estatais na era da rede global. Ijuí: Ed. Unijuí, 2016. v. III. p. 283-307.

MASCARENHAS, Thais; GOLÇALVES, Juliana. Grupos de Consumo Responsável: práticas de consumidores baseadas no comércio justo e solidário. In: STELZER, Joana; GOMES, Rosemary. (Orgs.). Comércio justo e solidário no Brasil e na América Latina. Florianópolis: Departamento de Ciências da Administração, UFSC, 2016, p. 119-140.

MARQUES, Camila Salgueiro da Purificação; BARBOSA, Claudia Maria; ARAÚJO, Sylvia Maria Cortês Bonifácio de. O STF e o conceito de desenvolvimento sustentável: uma análise empírica. In: BETTES, Janaina Maria; FURIATTI, Luiza de Araújo; SOUZA, Maria Augusta Oliveira de. (Orgs.). O direito entre o desenvolvimento e a sustentabilidade. Curitiba: CRV, 2017, p. 33-52.

McLUHAN, Marshall. Os meios de comunicação como extensão do homem. Tradução Décio Pignatari. 5. ed. São Paulo: Cultrix, 2001.

OLSSON, Giovanni. Relações Internacionais e seus atores na era da globalização. Curitiba: Juruá, 2003.

O poder da sociedade em rede e os atores não estatais. In: OLIVEIRA, Odete Maria de (Org.). Relações Internacionais, direito e poder: atores não estatais na era da rede global. Ijuí: Ed. Unijuí, 2016. v. III. p. 87-116.

OLIVEIRA, Odete Maria de. O protagonismo dos atores não estatais pacíficos e violentos: a revolução da rede de redes. In: (Org.). Relações Internacionais, Direito e Poder: atores não estatais na era da rede global. Ijuí: Ed. Unijuí, 2016. p. 39-86.

; ZEFERINO, Alisson. O protagonismo das organizações não governamentais como atores não estatais globais em rede. In: OLIVEIRA, Odete Maria de (Org.). Relações internacionais, direito e poder: atores não estatais na era da rede global. Ijuí: Ed. Unijuí, 2016. v. III. p. 117-179.

ORGANIZAÇÃO DAS NAÇOES UNIDAS. Relatório da Comissão Mundial sobre Meio Ambiente e Desenvolvimento n. 42/187. Disponível em: <http://www.un.org/documents/ga/res/42/ares42-187.htm>. Acesso em 01 ago. 2018.

ORGANIZAÇÃO DAS NAÇOES UNIDAS. Agenda 21 da Conferência das Nações Unidas sobre Meio Ambiente e Desenvolvimento. Disponível em: <http://www.onu.org.br/rio20/img/2012/01/agenda21.pdf>. Acesso em 01 ago. 2018b.

Transformando Nosso Mundo: A Agenda 2030 para o Desenvolvimento Sustentável. Disponível em: <https://nacoesunidas.org/pos2015/agenda2030/>. Acesso em: 01 ago. 2018c.

STELZER, Joana; TODESCAT, Marilda. GONÇALVES, Everton das Neves. O Projeto Ilha Rendada e o Comércio Justo: princípios normativos, práticas e desafios. In: STELZER, Joana; GOMES, Rosemary. (Orgs.). Comércio justo e solidário no Brasil e na América Latina. Florianópolis: Departamento de Ciências da Administração, UFSC, 2016, p. 19-54. 
GONÇALVES, Everton das Neves. Do Free Trade ao Fair Trade: Administração Pública para a gestão social do comércio exterior. Disponível em: <http://www.publicadireito.com.br/artigos/?cod=ee6e910d8a25e347>. Acesso em: 28 ago. 2018.

GONÇALVES, Everton das Neves. Transnacionalidade e Redes de Colaboração Solidária: sua importância na consolidação do Comércio Justo. Revista de Estudos Constitucionais, Hermenêutica e Teoria do Direito (RECHTD), São Leopoldo, jan/abr. 2017, p. 53-64.

WIEIRA, Keite. A certificação Fair Trade na WFTO: um estudo sobre princípios e critérios do para segurança consumidor. Revista de Direito, Globalização e Responsabilidade nas Relações de Consumo. Maranhão, v. 3, n. 2, p. 22 - 42, Jul/Dez. 2017.

UGARTE, David de. El poder de las redes. 2007. Disponível em: <http://lasindias.com/indianopedia/el-poder-de-las-redes>. Acesso em: 30 jul. 2018. 